\title{
Metabolic effects of insulin in a human model of ketoacidosis combining exposure to lipopolysaccharide and insulin deficiency: a randomised, controlled, crossover study in individuals with type 1 diabetes
}

\author{
Mads V. Svart ${ }^{1,2}$ - Nikolaj Rittig ${ }^{1,2}$ - Ulla Kampmann ${ }^{1}$. Thomas S. Voss ${ }^{1,2}$. \\ Niels Møller ${ }^{1,2} \cdot$ Niels Jessen $^{3,4}$
}

Received: 7 December 2016/Accepted: 15 March 2017 /Published online: 7 April 2017

(C) Springer-Verlag Berlin Heidelberg 2017

\begin{abstract}
Aims/hypothesis Diabetic ketoacidosis (DKA) is often caused by concomitant systemic inflammation and lack of insulin. Here we used an experimental human model to test whether and how metabolic responses to insulin are impaired in the early phases of DKA with a specific focus on skeletal muscle metabolism.

Methods Nine individuals with type 1 diabetes from a previously published cohort were investigated twice at Aarhus University Hospital using a $120 \mathrm{~min}$ infusion of insulin (3.0/1.5 $\mathrm{mU} \mathrm{kg}^{-1} \mathrm{~min}^{-1}$ ) after an overnight fast under: (1) euglycaemic conditions (CTR) or (2) hyperglycaemic ketotic conditions (KET) induced by an i.v. bolus of lipopolysaccharide and $85 \%$ reduction in insulin dosage. The primary outcome was insulin resistance in skeletal muscle. Participants were randomly assigned to one of the two arms at the time of screening using www.randomizer.org. The study was not blinded.

Results All nine volunteers completed the 2 days and are included in the analysis. Circulating concentrations of glucose and
\end{abstract}

Electronic supplementary material The online version of this article (doi:10.1007/s00125-017-4271-x) contains peer-reviewed but unedited supplementary material, which is available to authorised users.

Niels Jessen

niels.jessen@biomed.au.dk

1 Department of Internal Medicine and Endocrinology, Aarhus University Hospital, Aarhus, Denmark

2 Department of Clinical Medicine, Aarhus University Hospital, Aarhus, Denmark

3 Department of Clinical Pharmacology, Aarhus University Hospital, Aarhus, Denmark

4 Department of Biomedicine, Aarhus University, Wilhelm Meyers Alle 4, DK-8000 Aarhus C, Denmark 3-hydroxybutyrate increased during KET (mean \pm SEM $17.7 \pm 0.6 \mathrm{mmol} / \mathrm{l}$ and $1.6 \pm 0.2 \mathrm{mmol} / \mathrm{l}$, respectively), then decreased after insulin treatment $(6.6 \pm 0.7 \mathrm{mmol} / \mathrm{l}$ and $0.1 \pm 0.07 \mathrm{mmol} / \mathrm{l}$, respectively). Prior to insulin infusion (KET vs CTR) isotopically determined endogenous glucose production rates were $17 \pm 1.7 \mu \mathrm{mol} \mathrm{kg}^{-1} \mathrm{~min}^{-1}$ vs $8 \pm 1.3 \mu \mathrm{mol} \mathrm{kg}^{-1} \mathrm{~min}^{-1}$ $(p=0.003)$, whole body phenylalanine fluxes were $2.9 \pm 0.5 \mu \mathrm{mol} \mathrm{kg}{ }^{-1} \min ^{-1}$ vs $3.1 \pm 0.4 \mu \mathrm{mol} \mathrm{kg}{ }^{-1} \mathrm{~min}^{-1}$ $(p=0.77)$ and urea excretion rates were $16.9 \pm 2.4 \mathrm{~g} /$ day vs $7.3 \pm 1.7 \mathrm{~g} /$ day $(p=0.01)$. Insulin failed to stimulate forearm glucose uptake and glucose oxidation in KET compared with CTR $(p<0.05)$. Glycogen synthase phosphorylation was impaired in skeletal muscle.

Conclusions/interpretation In KET, hyperglycaemia is primarily driven by increased endogenous glucose production. Insulin stimulation during early phases of DKA is associated with reduced glucose disposal in skeletal muscle, impaired glycogen synthase function and lower glucose oxidation. This underscores the presence of muscle insulin resistance in the pathogenesis of DKA.

Trial registration www.clinicaltrials.gov (ID number: NCT02157155).

Funding This work was funded by the Danish Council for Strategic Research (grant no. 0603-00479B).

Keywords Clinical diabetes · Endogenous glucose production · Glucose transport · Hyperglycaemia · Insulin action $\cdot$ Insulin resistance $\cdot$ Insulin sensitivity $\cdot$ Skeletal muscle

\footnotetext{
Abbreviations

4eBP1 Eukaryotic translation initiation factor 4E binding protein 1

AS160 Akt substrate of $160 \mathrm{kDa}$
} 


$\begin{array}{ll}\text { CTR } & \text { Euglycaemic control conditions } \\ \text { DKA } & \text { Diabetic ketoacidosis } \\ \text { GS } & \text { Glycogen synthase } \\ \text { GSK3 } & \text { Glycogen synthase kinase 3 } \\ \text { HI } & \text { Hyperinsulinaemic infusion } \\ \text { KET } & \text { Hyperglycaemic ketotic conditions } \\ \text { LPS } & \text { Lipopolysaccharide } \\ \text { mTOR } & \text { Mammalian target of rapamycin } \\ \text { p70s6K } & \text { Ribosomal protein S6 kinase } \\ \text { PHB1 } & \text { Prohibitin 1 } \\ \text { RER } & \text { Respiratory exchange rate }\end{array}$

\section{Introduction}

Diabetic ketoacidosis (DKA) is a severe complication of diabetes caused by a deficiency of insulin often in combination with an infection. The insulin deficit has tissue-specific effects that mirror insulin action. In adipose tissue, the release of NEFA is increased owing to impaired inhibition of lipolysis [1]. In the liver, ketogenesis is stimulated and glucose output is increased due to reduced glycogen synthesis and accelerated gluconeogenesis. In skeletal muscle, glucose disposal is diminished due to reduced insulin-stimulated glucose uptake [2,3].

Conversely, insulin therapy reverses many of the processes underlying DKA, and immediate insulin treatment is important for a positive outcome. In adipose tissue, insulin treatment suppresses lipolysis, thereby limiting the supply of NEFA to the liver [4]. Concurrently, hepatic glucose production and ketogenesis are reduced [5]. The effects of insulin treatment on skeletal muscle during DKA are less well understood.

Under physiological conditions, muscle accounts for as much as $80 \%$ of glucose disposal after a glucose load [6]. The uptake of glucose into muscle is initiated by insulin-stimulated translocation of the glucose transporter GLUT4 from intracellular vesicles to the cell membrane. After transport into the muscle cell, glucose is either oxidised in the tricarboxylic acid cycle or incorporated into glycogen [6]. Several factors that are commonly associated with DKA, including increased NEFA levels and prolonged fasting, are potent inducers of insulin resistance in skeletal muscle $[7,8]$. The associated hyperglycaemia further impairs insulin action on skeletal muscle causing a vicious circle accelerating insulin resistance [9]. The capacity to increase glucose uptake in skeletal muscle therefore plays an essential role when reversing the hyperglycaemia, and the associated insulin resistance complicates treatment [10].

Previous investigations into insulin action during ketoacidosis have predominantly used animal models. These studies show that elevated circulating ketone body levels impair glucose uptake in muscle $[11,12]$. However, the toxic compound streptozocin is typically used in these animal models to induce hypoinsulinaemia. This reduces insulin production effectively, but as streptozocin also has toxic effects on the liver and the small intestine the model only reflects some aspects of type 1 diabetes mellitus. This, in combination with differences in substrate metabolism between rodents and humans, limits the clinical impact of these studies. Therefore, we have established a human model of DKA by combining insulin deprivation and lipopolysaccharide (LPS) injection in individuals with type 1 diabetes [13]. Using this approach, we aimed to investigate the mechanisms regulating glucose disposal in human skeletal muscle under the hypothesis that early phases of DKA are complicated by impaired insulin action in skeletal muscle.

\section{Methods}

Study design and participants The present study was designed as a randomised, controlled, crossover trial consisting of two experimental days, separated by at least 3 weeks, characterised by: (1) euglycaemic control conditions and a bolus of saline (154 mmol/l NaCl) (CTR) and (2) hyperglycaemic ketotic conditions (KET) induced by LPS administration combined with insulin deprivation, as previously described in detail [13]. The study was not blinded. Briefly, nine male volunteers with type 1 diabetes mellitus were selected using the following inclusion criteria: type 1 diabetes mellitus (c-peptide negative), male sex, 20-40 years of age, no medication other than insulin, BMI $19-26 \mathrm{~kg} / \mathrm{m}^{2}$ and without any comorbidities or diabetic complications. The study was carried out at Aarhus University Hospital.

Long-acting insulin was replaced by rapidly acting insulin (Insulin Actrapid; Novo Nordisk, Copenhagen, Denmark) to ensure adequate glycaemic control $24 \mathrm{~h}$ before each trial and to facilitate a switch to i.v. insulin on the experimental days. During CTR conditions, i.v. insulin was titrated to keep blood glucose within 5-7 mmol/l. During KET, insulin dosing was reduced to $15 \%$ of the participants' regular basal insulin need. LPS $(10,000$ USP Endotoxin, lot HOK354; United States Pharmacopeial Convention, Rockville, MD, USA) was given as a bolus infusion of $1 \mathrm{ng} / \mathrm{kg}$ body weight at $0 \mathrm{~min}$. LPS is used to mimic the presence of Gram-negative bacteria, causing an inflammatory immune response that results in a large increase in proinflammatory cytokines, such as TNF- $\alpha$, IL-6 and IL-10 [14].

The project was approved by the local ethics committee (1-10-72-98-14) in accordance with the Declaration of Helsinki and was registered at www.clinicaltrials.gov (ID number: NCT02157155). Participants were randomly assigned to one of the two arms at the time of screening using www.randomizer.org. All participants gave written informed consent prior to participation.

Preconditioning and hyperinsulinaemic infusion periods The participants were preconditioned from $0-300 \mathrm{~min}$ to either CTR or KET conditions. During the first half an hour (300-330 $\mathrm{min}$ ) of the hyperinsulinaemic infusion (HI) period a constant insulin infusion of $3.0 \mathrm{mU} \mathrm{kg}^{-1} \mathrm{~min}^{-1}$ was initiated 

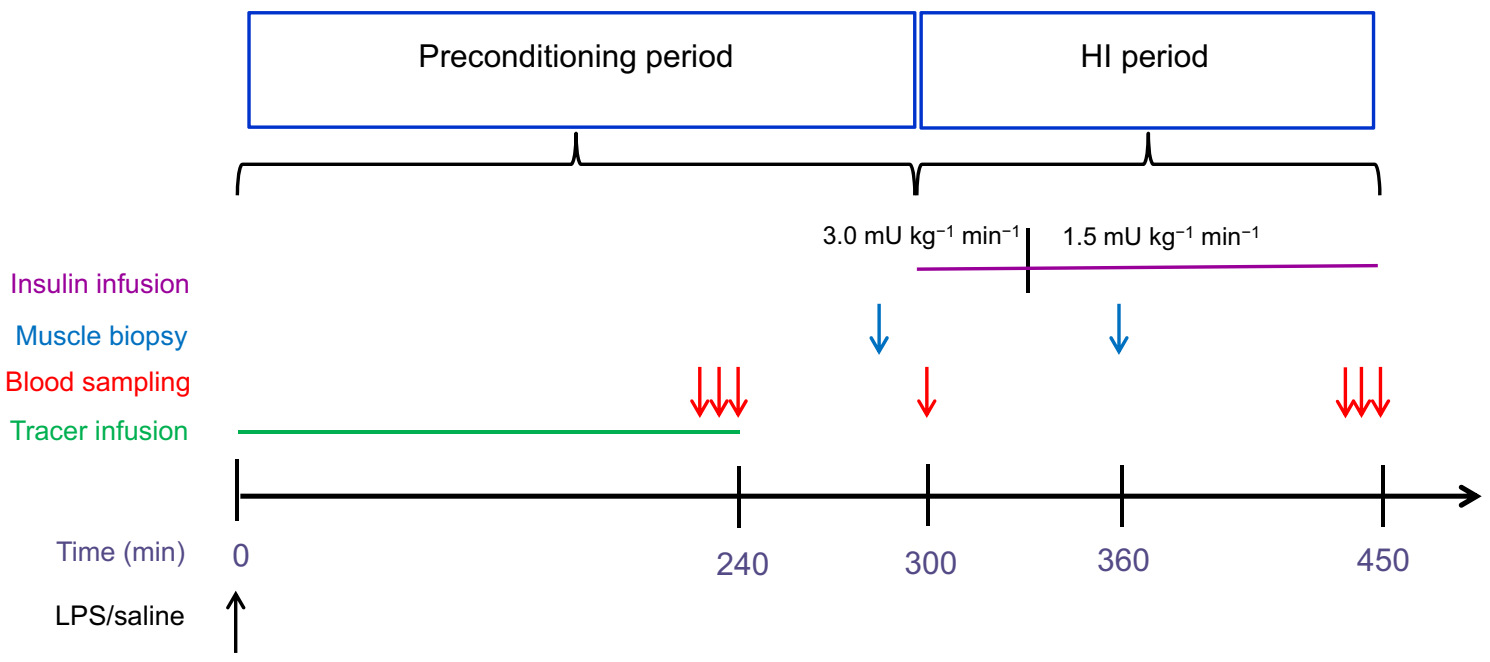

Fig. 1 Flowchart illustrating the study design showing the duration of insulin and tracer infusions, and the timing of muscle tissue biopsy, blood sampling and administration of LPS or saline

(Fig. 1). Subsequently, the insulin infusion was reduced to $1.5 \mathrm{mU} \mathrm{kg}^{-1} \mathrm{~min}^{-1}$ for the remaining study period (330-450 min). This hyperinsulinaemic condition mimics treatment after hospitalisation with DKA. Variable rates of $20 \%$ glucose infusion were used during CTR conditions to maintain euglycaemia at $\sim 5 \mathrm{mmol} / \mathrm{l}$. Plasma glucose was measured every $10 \mathrm{~min}$. Insulin and arterial and venous glucose were measured in triplicate at 430, 440 and $450 \mathrm{~min}$. The arteriovenous glucose difference was calculated as: (arterial glucose - venous glucose) $\times$ forearm blood flow

Outcomes and analytical methods We examined glucose disposal in skeletal muscle during the HI period using indirect calorimetry, plethysmography, muscle tissue biopsies and plasma substrate concentrations. Indirect calorimeter with a canopy (Oxycon Pro; Intra medic, Gentofte, Denmark) was applied at $210 \mathrm{~min}$ and $400 \mathrm{~min}$ to collect respiratory gases and estimate whole body energy expenditure, respiratory exchange rates (RER) and glucose oxidation rates as previously described [15].

Tracer kinetics D- $\left[3-{ }^{3} \mathrm{H}\right]$ glucose (GE Healthcare, Brøndby, Denmark) was administered as a bolus injection of $0.74 \mathrm{MBq}$ followed by continuous infusion of $0.44 \mathrm{MBq} / \mathrm{h}$ for $4 \mathrm{~h}$ until triplicate samples were drawn and analysed as described previously [16]. These samples were used to estimate endogenous glucose production at the end of the preconditioning period.

At $0 \mathrm{~min},\left[{ }^{15} \mathrm{~N}\right]$ phenylalanine (prime $0.75 \mathrm{mg} / \mathrm{kg}$, infusion rate $0.75 \mathrm{mg} \mathrm{kg}^{-1} \mathrm{~h}^{-1}$ ), $\left[{ }^{13} \mathrm{C}\right.$ ]urea (prime $390.6 \mathrm{mg}$, infusion rate $42 \mathrm{mg} / \mathrm{h}$ ), L- $\left[{ }^{2} \mathrm{H}_{4}\right]$ tyrosine (prime $0.6 \mathrm{mg} / \mathrm{kg}$, infusion rate $0.6 \mathrm{mg} / \mathrm{kg} / \mathrm{h}$ ) and a bolus of $\left[{ }^{15} \mathrm{~N}\right]$ tyrosine (prime $0.3 \mathrm{mg} / \mathrm{kg}$ ) were started. Triplicate samples were drawn on arterial and venous blood during the preconditioning period at 240-260 min. Isotopic enrichments of these blood samples were measured using GC-MS. Immediately following the collection of each blood sample, blood flow was measured using venous occlusion plethysmography across the forearm. In addition, urine was sampled throughout each study day to estimate urea excretion rates. Protein kinetics in muscle were calculated using the forearm model [17].

Muscle tissue biopsies Muscle biopsies were obtained from each participant from the vastus lateralis of the quadriceps femoris at $290 \mathrm{~min}$ (preconditioning period) and $360 \mathrm{~min}$ (HI period).

Muscle tissue was immediately snap-frozen in liquid nitrogen before storage at $-80^{\circ} \mathrm{C}$. All samples were subsequently homogenised in a buffer ( $\mathrm{pH} 7.4)$ containing $50 \mathrm{mmol} / 1$ HEPES, $137 \mathrm{mmol} / \mathrm{l} \mathrm{NaCl}, 20 \mathrm{mmol} / \mathrm{l} \mathrm{NaF}, 10 \mathrm{mmol} / \mathrm{l}$ $\mathrm{Na}_{4} \mathrm{P}_{2} \mathrm{O}_{7}, 5 \mathrm{mmol} / \mathrm{l}$ EDTA, $1 \mathrm{mmol} / \mathrm{l} \mathrm{MgCl}, 1 \mathrm{mmol} / 1 \mathrm{CaCl}_{2}$, $2 \mathrm{mmol} / \mathrm{l}$ sodium orthovanadate, Halt (Halt protease inhibitor cocktail no. 78438, Thermo Scientific, Waltham, MA, USA), $5 \mathrm{mmol} / \mathrm{l}$ nicotinamide, $10 \mu \mathrm{mol} / 1$ trichostatin A, $1 \%$ (vol./vol.) NP-40, and $10 \%$ (vol./vol.) glycerol. Samples were centrifuged after homogenisation at $14,000 \mathrm{~g}$ for $20 \mathrm{~min}$ and insoluble material was removed.

Protein samples were resolved by SDS-PAGE (4-12\% BisTris gels, Criterion XT System; BioRad, Hercules, CA, USA) and transferred to polyvinylidene fluoride membranes according to the manufacturer's instructions. Western blot analysis was performed using the following primary antibodies: v-Akt murine thymoma viral oncogene homologue (Akt) (total no. 4691, $\mathrm{Ser}^{473}$ no. 9271), Akt substrate of $160 \mathrm{kDa}$ (AS160) $\left(\mathrm{Thr}^{642}\right.$ no. 4288), glycogen synthase kinase 3 (GSK3) (total no. 5676, $\mathrm{Ser}^{21 / 9}$ no. 9331), glycogen synthase (GS) (total no. 3886, $\mathrm{Ser}^{641}$ no. 3891), mammalian target of rapamycin (mTOR) (total no. 2972, Ser $^{2448}$ no. 2971), eukaryotic translation initiation factor 4E binding protein 1 (4eBP1) (total no. $9644, \mathrm{Thr}^{46}$ no. 4923), ribosomal protein S6 kinase (p70s6K) (total no. 9202, Thr $^{389}$ no. 9205) and prohibitin 1 (PHB1) (no. 2426) from Cell Signaling (Danvers, MA, USA); and AS160 (total no. 07-741) from Merck 
Milipore (Darmstadt, Germany). Horseradish peroxidaseconjugated donkey anti-rabbit IgG (Amersham, GE Healthcare, Pittsburgh, PA, USA) was used as a secondary antibody. Proteins were visualised by chemiluminescence (Clarity Western ECL, BioRad) and ChemiDoc MP imaging system (BioRad), and quantified with Image Lab 5.0 (BioRad). Precision Plus All Blue protein standards were used as a marker of molecular mass (BioRad). Equal loading was ensured using stain-free technology [18]. Data are presented as individual dot plots showing a ratio of phosphorylated protein compared with total level of the same protein. Western blot membranes were stripped after analysing phosphorylated proteins to allow for total protein analysis on the same membranes. Further information is given in the electronic supplementary material (ESM) Table 1.

Skeletal muscle glycogen levels were assessed by a hexokinase enzymatic reaction as previously described [19]. Briefly, pulverised muscles were solubilised in $\mathrm{HCl}$ at $95^{\circ} \mathrm{C}$, subsequently neutralised with $\mathrm{NaOH}$ and centrifuged. Muscle glucose levels were assessed using hexokinase reagent (CIMA Scientific, De Soto, TX, USA) in the supernatant fraction.

Statistics and power calculations The primary endpoint was glucose uptake in skeletal muscle estimated from arteriovenous glucose difference in $\mathrm{mmol} / \mathrm{l}$ and blood flow. The power calculation for the primary endpoint as a comparison of two paired means with significance level $=0.05$, power $=0.90$, difference of means $=1.0 \mathrm{mmol} / \mathrm{l}$ and $\mathrm{SD}$ of the mean $=0.3 \mathrm{mmol} / \mathrm{l}$. This gave a sample size of $n=4$. We included nine participants to ensure secondary outcomes as well.

Results are presented as means \pm SEM, unless otherwise specified. Normal distribution of data was ensured by inspection of QQ-plots. Statistical associations between the two trial days was tested using a paired $t$ test and two-way repeated measure ANOVA analysis when relevant. A $p$ value $<0.05$ was considered significant. Graphing and statistical analyses were completed using Sigmaplot 11 (Systat Software, San Jose, CA, USA) and Stata 13 (Stata, College Station, TX, USA), respectively.

\section{Results}

The characteristics of the nine participants and details of the inflammatory response have been published previously [13]. In summary, the participants had an average $\mathrm{HbA}_{1 \mathrm{c}}$ of $7.7 \%$ $(61 \mathrm{mmol} / \mathrm{mol})$, diabetes duration of $14 \pm 2$ years, daily insulin of $0.7 \pm 0.4 \mathrm{U} \mathrm{kg}^{-1}$ day $^{-1}$, BMI of $25 \pm 1 \mathrm{~kg} / \mathrm{m}^{2}$ and a median age of 30 years (range 21-40). There was a 100-200-fold increase in TNF- $\alpha$, IL- 6 and IL-10 during KET [13]. The key metabolic variables from the preconditioning period are presented in Table 1.

Insulin-stimulated glucose disposal is impaired in KET Arteriovenous glucose differences during $\mathrm{HI}$ were $>1 \mathrm{mmol} / \mathrm{l}$
Table 1 Metabolic status at $t=0$ and right before hyperinsulinaemic infusion was started

\begin{tabular}{lccc}
\hline \multirow{2}{*}{ Characteristic } & \multirow{2}{*}{$\begin{array}{l}\text { Metabolic } \\
\text { status at } t=0\end{array}$} & \multicolumn{2}{c}{ Metabolic status at $t=270$} \\
\cline { 3 - 4 } & CTR & \multicolumn{1}{l}{ CTR } & \multicolumn{1}{c}{ KET } \\
\hline $\mathrm{pH}$ & $7.41 \pm 0.01$ & $7.4 \pm 0.01$ & $7.39 \pm 0.01$ \\
Base excess (mmol/1) & $1.1 \pm 0.6$ & $-0.03 \pm 0.4$ & $-2.9 \pm 0.6^{*}$ \\
Glucose (mmol/l) & $6.9 \pm 0.7$ & $6.8 \pm 0.4$ & $17.7 \pm 0.6^{*}$ \\
NEFA (mmol/l) & $0.5 \pm 0.1$ & $0.6 \pm 0.1$ & $1.4 \pm 0.1^{*}$ \\
Glucagon (pg/ml) & $40.4 \pm 4.5$ & $38.9 \pm 5.8$ & $95.1 \pm 18.8^{*}$ \\
3-Hydroxybutyrate & $0.1 \pm 0.1$ & $0.3 \pm 0.1$ & $1.6 \pm 0.2^{*}$ \\
$\quad(\mathrm{mmol} / \mathrm{l})$ & & & \\
Cortisol (ng/ml) & $139.7 \pm 53.1$ & $92.9 \pm 30.7$ & $291.4 \pm 34.4^{*}$ \\
\hline
\end{tabular}

Data are expressed as mean \pm SEM

${ }^{*} p<0.05$ for paired comparison of CTR with KET at $t=270$

$\mathrm{pH}$, glucose, NEFA and 3-hydroxybutyrate have all been published previously [13]

greater during CTR $(1.2 \mathrm{mmol} / \mathrm{l})$ compared with KET $(-0.2 \mathrm{mmol} / \mathrm{l} ; p<0.01)$ (Fig. 2a). Skeletal muscle glucose uptake during the $\mathrm{HI}$ period was $>2.5 \mathrm{mmol} / \mathrm{min}$ larger during CTR $\left(2.2 \mathrm{mmol}[100 \mathrm{mg}]^{-1} \mathrm{~min}^{-1}\right)$ compared with KET $(-0.5 \mathrm{mmol} / 100 \mathrm{mg} / \mathrm{min} ; p<0.05)$ (Fig. $2 \mathrm{~b}$ ), demonstrating impaired insulin-stimulated glucose uptake in skeletal muscle. Blood flow was slightly higher during KET $(2.3 \pm 0.4 \mathrm{ml} / \mathrm{min})$ compared with CTR $(2.0 \pm 0.2 \mathrm{ml} / \mathrm{min} ; p=0.03)$.

During the HI, the glucose oxidation rate was $40 \%$ higher in CTR (1268 kJ/day; $p<0.05)$ (Fig. 2c). Energy expenditure was similar during the $\mathrm{HI}$ period on both experimental days. The RER was higher in CTR $(0.87 \pm 0.03)$ compared with KET $(0.81 \pm 0.01)$, but the difference was only borderline significant ( $p=0.07$; Fig. $2 \mathrm{~d}$ ). We found no alteration in mitochondrial content estimated from PHB1 levels (Fig. 2e).

During the preconditioning period the endogenous glucose production assessed by isotope dilution was twofold higher in KET $\left(17 \pm 1.7 \mu \mathrm{mol} \mathrm{kg}^{-1} \mathrm{~min}^{-1}\right)$ compared with CTR $\left(8 \pm 1.3 \mu \mathrm{mol} \mathrm{kg}{ }^{-1} \mathrm{~min}^{-1} ; p=0.003\right)$. The associated insulin levels before the $\mathrm{HI}$ period were $27 \mathrm{pmol} / \mathrm{l}$ for KET and $85 \mathrm{pmol} / \mathrm{l}$ for CTR. During the HI, plasma glucose levels decreased in KET but DKA-associated hyperglycaemia was not normalised (Fig. 3a). Despite the same weight-adjusted amounts of insulin being infused during the HI, insulin concentrations were $\approx 15 \%$ higher in KET than CTR $(p<0.05)$ (Fig. 3b).

At the end of the preconditioning period, cortisol levels were threefold higher in KET $(291 \pm 34 \mathrm{ng} / \mathrm{ml})$ compared with CTR $(93 \pm 31 \mathrm{ng} / \mathrm{ml} ; p<0.001)$, adrenalin levels did not differ significantly between KET $(133 \pm 88 \mathrm{pg} / \mathrm{l})$ and CTR $(42 \pm 11 \mathrm{pg} / 1 ; p>0.05)$ and glucagon levels were nearly threefold higher during KET $(95 \pm 19 \mathrm{pg} / \mathrm{ml})$ compared with CTR $(38 \pm 6 \mathrm{pg} / \mathrm{ml} ; p<0.05)$. During the HI, cortisol decreased in KET, while no effect of hyperinsulinaemia was observed in CTR. Glucagon remained elevated by $50 \%$ in KET 
Fig. 2 Arteriovenous (AV) glucose difference (a) and glucose uptake in $100 \mathrm{mg}$ skeletal muscle per min (b) were measured using a triplicate blood sample at 240-260 min to calculate an average ('CTR + insulin', $n=7$ ). This individual average is shown in a dot plot with a mean value. Indirect calorimetry was applied at $210 \mathrm{~min}$ and $400 \mathrm{~min}$. Glucose oxidation (c) and RER (d) are shown in an individual dot plot with a mean value. PHB1 content in muscle tissue biopsies (e) taken at $290 \mathrm{~min}$ and $360 \mathrm{~min}$. The individual ratio of PHB1 to total intramuscular protein is shown as dot plot with a mean value. Representative blots are shown above the dot plots (blots have been cropped and rearranged). $\mathrm{HI}$ is indicated by insulin $+/-$ (HI started at $300 \mathrm{~min}$ ). $n=9$ for CTR and KET. Shapes in dot plots represent different individuals. Two-way repeated measures ANOVA analysis was used to test for differences between the two days; $* p<0.05$
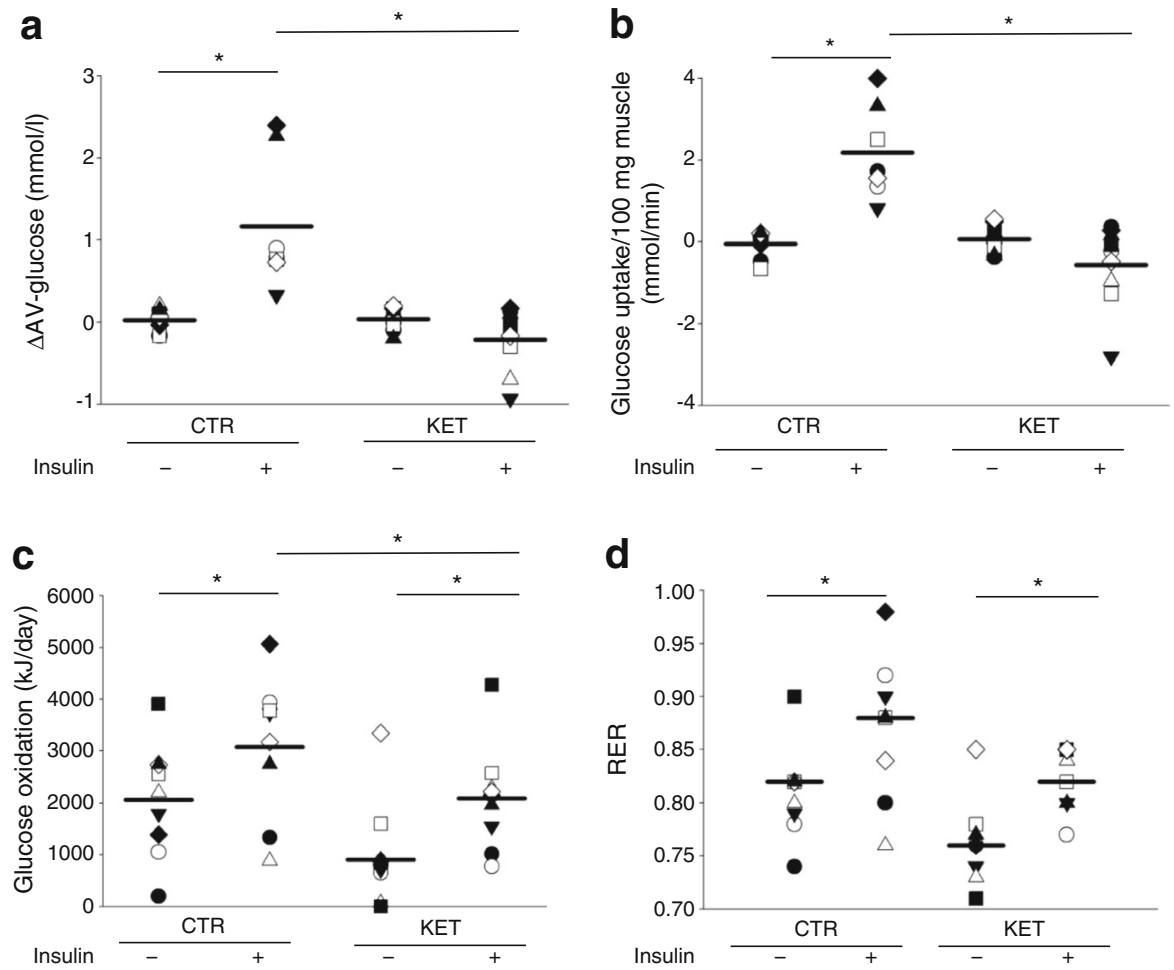

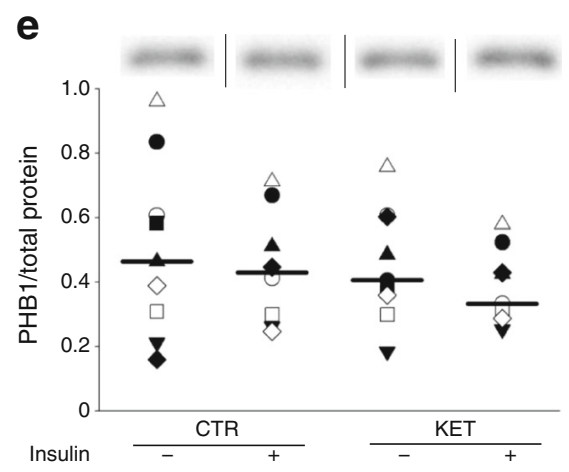

$(48.9 \pm 5.0 \mathrm{pg} / \mathrm{ml})$ compared with CTR $(31.3 \pm 4.7 \mathrm{pg} / \mathrm{ml}$; $p<0.01)$ during the HI, while adrenalin was unaffected.

\section{Insulin signalling through Akt/AS160 is increased in KET} Insulin stimulates glucose uptake through GLUT4 after binding to its receptor in skeletal muscle by subsequent activation of a signalling cascade. To assess insulin signalling in skeletal muscle during early phase DKA, we investigated phosphorylation of Akt and AS160, critical nodes in insulin signal transduction to glucose transport [20]. During the HI period, Akt phosphorylation at $\mathrm{Ser}^{473}$ increased on both trial days, but the increase from the preconditioning period to the HI period was twofold higher in KET compared with CTR $(p<0.05$ for interaction; Fig. 4a). Downstream of Akt, the HI was associated with an increase in $\mathrm{Thr}^{642}$ phosphorylation of AS160 that was twofold greater in KET than CTR $(p<0.05$ for interaction; Fig. 4b). We also measured GLUT4 content, which did not change (data not shown).

Insulin-stimulated regulation of GS phosphorylation is impaired in KET GS, the rate-limiting enzyme for glycogen synthesis, is inactivated by phosphorylation at $\operatorname{Ser}^{641}$ [20]. During the HI period, insulin reduced GS Ser ${ }^{641}$ phosphorylation in both CTR and KET, but as shown in Fig. 4c insulininduced reduction in phosphorylation was $\sim 50 \%$ lower for KET. GSK3 is the upstream kinase for GS Ser ${ }^{641}$ but, similar to Akt and AS160, insulin-induced GSK3 phosphorylation was enhanced in KET (Fig. 4d). We did not find any statistically significant difference in muscle tissue glycogen content.

Insulin-mediated suppression of lipolysis is impaired in KET Hyperketonaemia was suppressed to equal levels in 
Fig. 3 Plasma glucose (a) was measured every $10 \mathrm{~min}$. Black circles illustrate the mean value $( \pm \mathrm{SE})$ on the KET day and white circles illustrate the mean value $( \pm$ SE) on the CTR day. Plasma insulin (b) was measured at $300 \mathrm{~min}$ and $450 \mathrm{~min}$. Plasma 3-hydroxybutyrate (3-OHB) (c) was measured at $300 \mathrm{~min}$ and 450 min. Plasma NEFA (d) was measured at $260 \mathrm{~min}$ and 450 min. Plasma insulin, 3-OHB and NEFA concentrations are shown on individual dot plots with mean values. $n=9$ for CTR and KET. Shapes in dot plots represent different individuals. HI is indicated by insulin $+/-$ (HI started at $300 \mathrm{~min}$ ). Two-way repeated measures ANOVA analysis was used to test for differences between the two days; $* p<0.05$
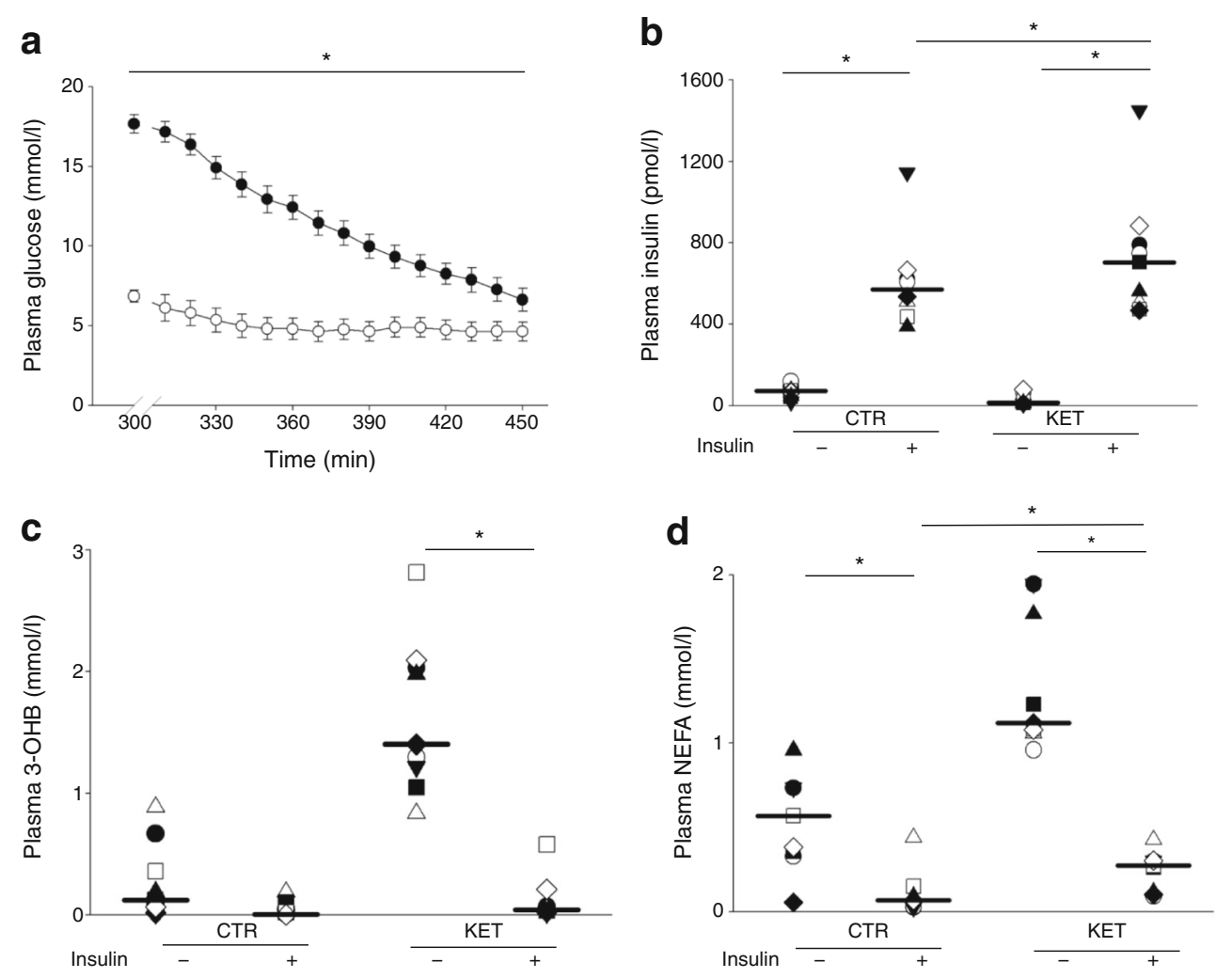

both CTR and KET (Fig. 3c). However, during the HI, insulin-stimulated suppression of NEFA levels was impaired in KET compared with CTR $(0.26$ vs $0.12 \mathrm{mmol} / \mathrm{l}$; $p<0.05$ ) (Fig. 3d). This was associated with increased lipid oxidation in KET $(3640 \mathrm{~kJ} /$ day $)$ compared with CTR $(2356 \mathrm{~kJ} /$ day $)$, although this difference was not statistically significant $(p=0.17)$.

Increased protein turnover and urea excretion but no changes in muscle balances in KET Phenylalanine, thyrosine and urea tracers together with pletysmography and indirect calorimetry were used to investigate skeletal muscle and whole body protein balance prior to the HI period. Urine nitrogen excretion doubled from $7.3 \pm 1.7 \mathrm{~g} /$ day (CTR) to $16.9 \pm 2.4 \mathrm{~g} /$ day (KET; $p<0.05$ ), but this was not associated with detectable differences in skeletal muscle protein synthesis, breakdown or balance; phenylalanine fluxes were $2.9 \pm 0.5 \mu \mathrm{mol} \mathrm{kg} \mathrm{kg}^{-1} \mathrm{~min}^{-1}$ vs $3.1 \pm 0.4 \mu \mathrm{mol} \mathrm{kg}{ }^{-1} \min ^{-1}(p=0.77)$. In accordance with the increased nitrogen excretion, whole body protein breakdown was $30 \%$ higher in KET $\left(42.7 \mu \mathrm{mol} \mathrm{kg} \mathrm{k} \mathrm{h}^{-1}\right)$ compared with CTR $\left(31.4 \mu \mathrm{mol} \mathrm{kg}{ }^{-1} \mathrm{~h}^{-1} ; p<0.001\right)$ and synthesis increased by $40 \%$ in KET (39.9 $\mu \mathrm{mol} \mathrm{kg} \mathrm{kg}^{-1} \mathrm{~h}^{-1}$ ) compared with CTR $\left(28.4 \mu \mathrm{mol} \mathrm{kg}{ }^{-1} \mathrm{~h}^{-1} ; p<0.001\right)$. Ultimately, these changes did not affect whole body protein balance. Urea turnover tended to be increased in KET $\left(347 \pm 44 \mu \mathrm{mol} \mathrm{kg}{ }^{-1} \mathrm{~h}^{-1}\right)$ compared with CTR (279 $\left.\pm 29 \mu \mathrm{mol} \mathrm{kg}{ }^{-1} \mathrm{~h}^{-1} ; p=0.13\right)$.

Calculated from indirect calorimetry and urinary nitrogen excretion during the HI period, we found no difference in protein oxidation (KET $2238 \mathrm{~kJ} /$ day vs CTR $1749 \mathrm{~kJ} /$ day; $p=0.25$ ). The $\mathrm{HI}$ increased insulin signalling to protein synthesis through mTOR and 4eBP1 (Fig. 5a,c), whereas p70s6K showed no difference during HI (Fig. 5b). However, there were no differences between KET and CTR conditions.

\section{Discussion}

In general, hyperglycaemia is an important component of DKA [21]. The major findings of this study are that the early phases of DKA in individuals with type 1 diabetes mellitus are associated with elevated endogenous glucose production, pronounced insulin resistance and impaired glucose disposal in skeletal muscle. In this study, insulin treatment during early phases of DKA elevated circulating insulin levels to $\sim 600 \mathrm{pmol} / \mathrm{l}$, which is high in the normal range of postprandial levels. The slightly higher insulin level observed during steady state (KET) reflects differences in insulin breakdown and could be a consequence of LPS-induced inflammation of the liver [22]. However, despite significant insulin stimulation we failed to detect an increased glucose disposal over forearm muscle. Therefore, it is probably necessary to impose supraphysiological insulin levels to ensure increased glucose disposal in skeletal muscle during DKA.

Stress hormones, such as cortisol, adrenalin and glucagon, are known to accompany inflammation and contribute to insulin resistance [23-25]; however, in our model of DKA only increases in glucagon levels persisted throughout the 
Fig. 4 Western blotting was used to measure intramuscular content of Akt (a), AS160 (b), GS (c), GSK3 (d) and their respective phosphorylations. The individual ratio of each phosphorylated protein to total amount of that protein is shown as a dot plot with a mean value. Representative blots are shown above each dot plot (blots have been cropped and rearranged, original blots can be obtained upon request). Muscle tissue biopsies were taken at $290 \mathrm{~min}$ and $360 \mathrm{~min} . n=8$ for CTR and KET. Shapes in dot plots represent different individuals. HI is indicated by insulin $+/-$ (HI started at $300 \mathrm{~min}$ ). Two-way repeated measures ANOVA analysis was used to test for differences between the two days; * $p<0.05$ a

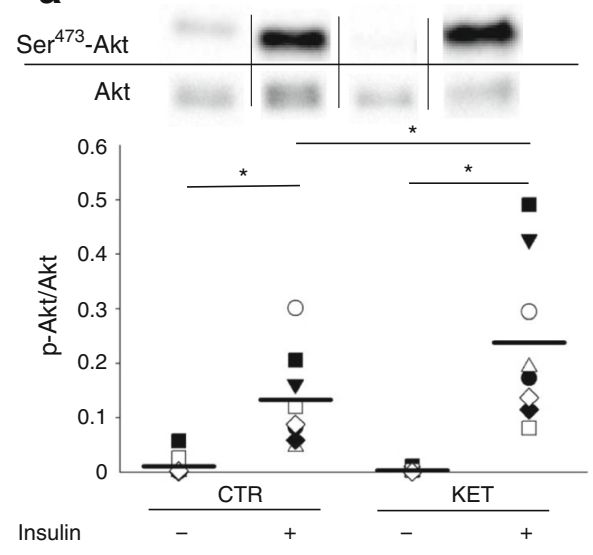

C
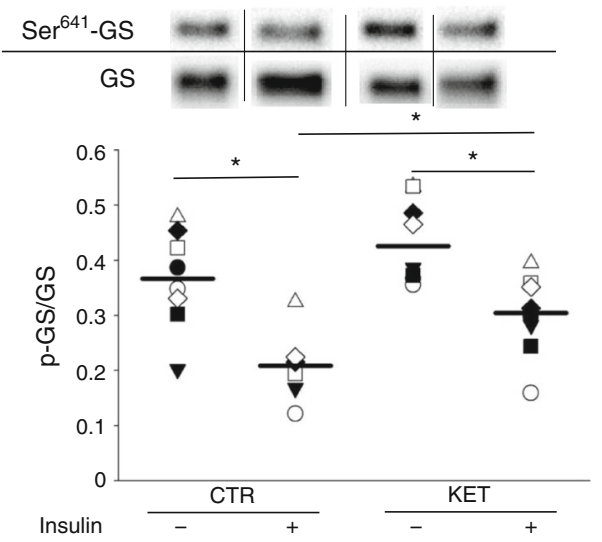

b

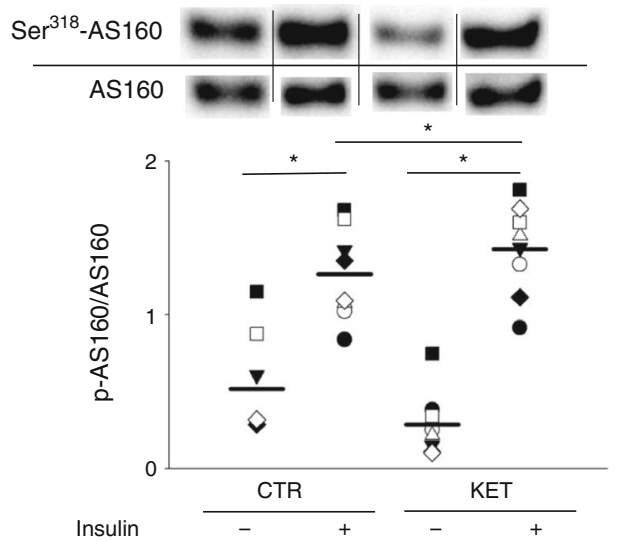

d
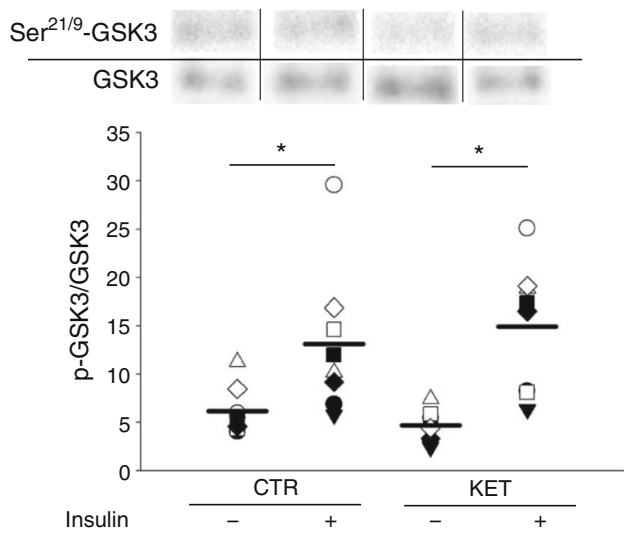

HI period. Glucagon receptors have not been identified on skeletal muscle and the elevated glucagon levels are unlikely to directly induce insulin resistance in skeletal muscle. However, glucagon may increase endogenous glucose production in the liver and thereby contribute to persisting hyperglycaemia [26]. The elevated glucose levels will induce insulin resistance in skeletal muscle and glucagon could therefore contribute to the impaired insulin action in skeletal muscle indirectly. In septic individuals, in general, the aim is to reduce hyperglycaemia in order to prevent oxidative stress and further inflammation [27]. Studies have shown that hyperglycaemia compromises the innate immune system and is additive to the sepsis, increasing both mortality and morbidity rates (both higher in this group) [28]. Our data shows that insulin resistance during early phases of DKA is not solely explained by increases in stress hormone level, but may include other effects on liver and skeletal muscle.

Despite profound inhibition of insulin-stimulated glucose uptake in skeletal muscle, insulin stimulation increased signalling through Akt and AS160. In skeletal muscle, glucose is taken up via GLUT4 and oxidised or stored as glycogen [6]. It is not known if the enhanced insulin-stimulated AS160 $\mathrm{Thr}^{642}$ phosphorylation observed during the HI period under KET would translate into greater GLUT4 translocation. Insulin resistance in type 2 diabetes mellitus is associated with impaired insulin-stimulated GLUT4 translocation in skeletal muscle [29]. Alternatively, glucose uptake could be impaired due to diminished GLUT4 transporter activity or reduced glucose metabolism leading to a lower gradient for passive transport through GLUT4 [30, 31]. However, circulating glucose levels were elevated throughout KET, and this would increase the gradient for glucose transport across the sarcolemma. It is therefore likely that DKA is associated with impaired GLUT4 translocation.

KET was associated with compromised glycogen synthesis evident by increased phosphorylation of the inhibiting site $3 \mathrm{a}$ [32]. In addition to regulation by phosphorylation, GS activity is dependent on substrate availability, and the ablated glucose uptake in skeletal muscle is likely to contribute further to impairment of glycogen synthesis [33, 34]. In spite of ablated glucose uptake in skeletal muscle, insulin stimulation was associated with increased glucose oxidation. This was determined on a whole body level and glucose oxidation in tissues other than skeletal muscle will have contributed. Prolonged hyperglycaemia and associated increases in oxidative stress can cause mitochondrial dysfunction [35]. We did not find evidence to support during the early phases of DKA a 
Fig. 5 Western blotting was used to measure intramuscular content of mTOR (a), p70s6k (b) and their respective phosphorylations. Intramuscular content of nonphosphorylated 4eBP1 (c). The individual ratio of each phosphorylated/nonphosphorylated protein to total amount of that protein is shown as a dot plot with a mean value. Representative blots are shown above each dot plot (blots have been cropped and rearranged, original blots can be obtained upon request). Muscle tissue biopsies were taken at $290 \mathrm{~min}$ and $360 \mathrm{~min} . n=8$ for CTR and KET. Shapes in dot plots represent different individuals. HI is indicated by insulin $+/-$ (HI started at $300 \mathrm{~min}$ ). Two-way repeated measures ANOVA analysis was used to test for differences between the two days; $* p<0.05$
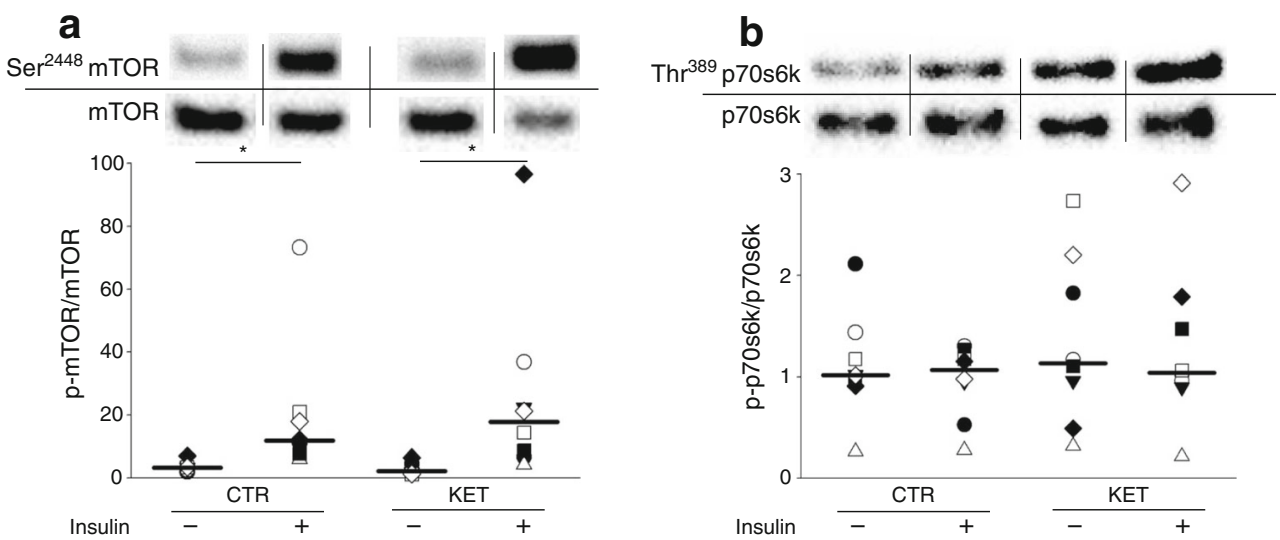

reduction of mitochondrial content in skeletal muscle, although reductions in mitochondrial function cannot be excluded.

Lipid metabolism is profoundly affected by KET and elevated NEFA levels are a potent inducer of insulin resistance in skeletal muscle [36]. This is independent of alterations in insulin signalling for glucose transport and therefore in agreement with the observed insulin signalling during $\operatorname{KET}[7,37]$. The precipitating steps of DKA include increased ketogenesis [13]; in rats, elevated ketone bodies impair glucose uptake in skeletal muscle. Therefore, this could have contributed to the insulin resistance during these early phases of DKA [12]. Despite slightly higher insulin levels during KET, suppression of lipolysis was impaired. This demonstrates insulin resistance in adipose tissue during KET. In contrast, the suppression of ketogenesis by insulin was intact indicating that hepatic insulin action was normal.

We did not detect any effect of KET on total protein balance. This was evident both on a whole body level and on a muscular level, and this is in accordance with previous studies $[38,39]$. An increased protein turnover on a whole body level was expected as inflammation was induced [40]. This finding was supported by no differences in protein oxidation between the two conditions and equal insulin-stimulated changes in intracellular signalling pathways for protein synthesis as reflected by mTOR, p70s6K and 4eBP1. Skeletal muscle break down is shown to proceed for days following acute inflammatory conditions after surgery if no supplement is given and acidosis promotes negative protein balance primarily by increased break down $[41,42]$. We allowed KET and CTR conditions to continue for five consecutive hours after LPS/ saline administration. During KET, acidosis was buffered by bicarbonate, and $\mathrm{pH}$ did not change to acidotic levels. It is likely that prolonged DKA lasting for days will augment protein balance but this cannot be determined using our model of the early phases of DKA in humans. In addition, LPS mimics a Gram-negative infection and, therefore, our conclusion is limited to this scenario.

In conclusion, early stages of DKA in humans are characterised by increased levels of glucagon and elevated endogenous glucose production. Insulin stimulation during the early phases of DKA is associated with impaired stimulation of glucose uptake in skeletal muscle. The skeletal muscle insulin resistance is associated with increased insulinstimulated signalling through Akt and AS160 but impaired insulin signalling for glycogen synthesis. Together these findings demonstrate that profound insulin resistance in skeletal muscle complicates insulin treatment of DKA.

Acknowledgements The authors would like to thank A. Mengel, K. Mathiassen, H. Pedersen and H. Zibrandtsen from the Department of Clinical Medicine, Aarhus University Hospital, Denmark, for their excellent technical assistance and consistent work throughout the study. Likewise, the authors would like to thank the nine participants for participation and completion of the study days. 
Data availability Data and original blots are available upon request, but permission must, in selected cases, first be obtained from the Danish Data Protection Agency.

Funding This work was funded by the Danish Council for Strategic Research (grant no. 0603-00479B).

Duality of interest The authors declare that there is no duality of interest associated with this manuscript.

Author contribution MVS contributed to the research design and conduct, data analysis, and writing and final approval of the manuscript. TSV, $\mathrm{NR}$ and UK contributed to the research design and conduct, revised the manuscript critically and gave final approval of the manuscript. NM and $\mathrm{NJ}$ contributed to the research design, data analysis, and writing and final approval of the manuscript. NJ is the guarantor of this work and, as such, had full access to all the data in the study and takes responsibility for the integrity of the data and the accuracy of the data analysis.

\section{References}

1. Krzentowski G, Scheen A, Castillo M, Luyckx AS, Lefebvre PJ (1983) A 6-hour nocturnal interruption of a continuous subcutaneous insulin infusion: 1. Metabolic and hormonal consequences and scheme for a prompt return to adequate control. Diabetologia 24: 314-318

2. Miles JM, Rizza RA, Haymond MW, Gerich JE (1980) Effects of acute insulin deficiency on glucose and ketone body turnover in man: evidence for the primacy of overproduction of glucose and ketone bodies in the genesis of diabetic ketoacidosis. Diabetes 29: 926-930

3. Cline GW, Magnusson I, Rothman DL, Petersen KF, Laurent D, Shulman GI (1997) Mechanism of impaired insulin-stimulated muscle glucose metabolism in subjects with insulin-dependent diabetes mellitus. J Clin Invest 99:2219-2224

4. Avogaro A, Valerio A, Gnudi L et al (1992) The effects of different plasma insulin concentrations on lipolytic and ketogenic responses to epinephrine in normal and type 1 (insulin-dependent) diabetic humans. Diabetologia 35:129-138

5. Lin HV, Accili D (2011) Hormonal regulation of hepatic glucose production in health and disease. Cell Metab 14:9-19

6. DeFronzo RA, Jacot E, Jequier E, Maeder E, Wahren J, Felber JP (1981) The effect of insulin on the disposal of intravenous glucose. Results from indirect calorimetry and hepatic and femoral venous catheterization. Diabetes 30:1000-1007

7. Gormsen LC, Jessen N, Gjedsted J et al (2007) Dose-response effects of free fatty acids on glucose and lipid metabolism during somatostatin blockade of growth hormone and insulin in humans. J Clin Endocrinol Metab 92:1834-1842

8. Vendelbo MH, Clasen BF, Treebak JT et al (2012) Insulin resistance after a 72-h fast is associated with impaired AS160 phosphorylation and accumulation of lipid and glycogen in human skeletal muscle. Am J Phys Endocrinol Metab 302:E190-E200

9. Bensellam M, Laybutt DR, Jonas JC (2012) The molecular mechanisms of pancreatic beta-cell glucotoxicity: recent findings and future research directions. Mol Cell Endocrinol 364:1-27

10. Barrett EJ, DeFronzo RA, Bevilacqua S, Ferrannini E (1982) Insulin resistance in diabetic ketoacidosis. Diabetes 31:923-928

11. Oshida Y, Iwao N, Ohsawa I, Sato J, Nakao T, Sato Y (1998) Effect of insulin on intramuscular 3-hydroxybutyrate levels in diabetic rats. Horm Metab Res 30:70-71
12. Okuda Y, Kawai K, Ohmori H, Yamashita K (1991) Ketone body utilization and its metabolic effect in resting muscles of normal and streptozocin-diabetic rats. Endocrinol Jpn 38:245-251

13. Svart M, Kampmann U, Voss T et al (2016) Combined insulin deficiency and endotoxin exposure stimulate lipid mobilization and alter adipose tissue signaling in an experimental model of ketoacidosis in subjects with type 1 diabetes: a randomized, controlled, cross over trial. Diabetes 65:1380-1386

14. Andreasen AS, Krabbe KS, Krogh-Madsen R, Taudorf S, Pedersen BK, Moller K (2008) Human endotoxemia as a model of systemic inflammation. Curr Med Chem 15:1697-1705

15. Ferrannini E (1988) The theoretical bases of indirect calorimetry: a review. Metab Clin Exp 37:287-301

16. Moller N, Jensen MD, Rizza RA, Andrews JC, Nair KS (2006) Renal amino acid, fat and glucose metabolism in type 1 diabetic and non-diabetic humans: effects of acute insulin withdrawal. Diabetologia 49:1901-1908

17. Rittig N, Bach E, Thomsen HH et al (2016) Amino acid supplementation is anabolic during the acute phase of endotoxin-induced inflammation: a human randomized crossover trial. Clin Nutr 35: $322-330$

18. Gurtler A, Kunz N, Gomolka M et al (2013) Stain-free technology as a normalization tool in western blot analysis. Anal Biochem 433: 105-111

19. Bondar RJ, Mead DC (1974) Evaluation of glucose-6-phosphate dehydrogenase from Leuconostoc mesenteroides in the hexokinase method for determining glucose in serum. Clin Chem 20:586-590

20. Taniguchi CM, Emanuelli B, Kahn CR (2006) Critical nodes in signalling pathways: insights into insulin action. Nat Rev Mol Cell Biol 7:85-96

21. Steenkamp DW, Alexanian SM, McDonnell ME (2013) Adult hyperglycemic crisis: a review and perspective. Curr Diab Rep 13: 130-137

22. Cani PD, Amar J, Iglesias MA et al (2007) Metabolic endotoxemia initiates obesity and insulin resistance. Diabetes 56:1761-1772

23. Rizza RA, Mandarino LJ, Gerich JE (1982) Cortisol-induced insulin resistance in man: impaired suppression of glucose production and stimulation of glucose utilization due to a post-receptor detect of insulin action. J Clin Endocrinol Metab 54:131-138

24. Deibert DC, DeFronzo RA (1980) Epinephrine-induced insulin resistance in man. J Clin Invest 65:717-721

25. Patarrao RS, Lautt WW, Macedo MP (2015) Acute glucagon induces postprandial peripheral insulin resistance. PLoS One 10: e0127221

26. Ramnanan CJ, Edgerton DS, Kraft G, Cherrington AD (2011) Physiologic action of glucagon on liver glucose metabolism. Diabetes Obes Metab 13(Suppl 1):S118-S125

27. Dellinger RP, Levy MM, Rhodes A et al (2013) Surviving sepsis campaign: international guidelines for management of severe sepsis and septic shock, 2012. Intensive Care Med 39:165-228

28. Turina M, Fry DE, Polk HC Jr (2005) Acute hyperglycemia and the innate immune system: clinical, cellular, and molecular aspects. Crit Care Med 33:1624-1633

29. Ryder JW, Yang J, Galuska D et al (2000) Use of a novel impermeable biotinylated photolabeling reagent to assess insulin- and hypoxia-stimulated cell surface GLUT4 content in skeletal muscle from type 2 diabetic patients. Diabetes 49:647-654

30. Zaid H, Talior-Volodarsky I, Antonescu C, Liu Z, Klip A (2009) GAPDH binds GLUT4 reciprocally to hexokinase-II and regulates glucose transport activity. Biochem J 419:475-484

31. Bryant NJ, Govers R, James DE (2002) Regulated transport of the glucose transporter GLUT4. Nat Rev Mol Cell Biol 3:267-277

32. Bienso RS, Olesen J, Gliemann L et al (2015) Effects of exercise training on regulation of skeletal muscle glucose metabolism in elderly men. J Gerontol A Biol Sci Med Sci 70:866-872 
33. Halse R, Bonavaud SM, Armstrong JL, McCormack JG, Yeaman SJ (2001) Control of glycogen synthesis by glucose, glycogen, and insulin in cultured human muscle cells. Diabetes 50:720-726

34. Rossetti L, Giaccari A (1990) Relative contribution of glycogen synthesis and glycolysis to insulin-mediated glucose uptake. A dose-response euglycemic clamp study in normal and diabetic rats. $\mathrm{J}$ Clin Invest 85:1785-1792

35. Giacco F, Brownlee M (2010) Oxidative stress and diabetic complications. Circ Res 107:1058-1070

36. Randle PJ, Garland PB, Hales CN, Newsholme EA (1963) The glucose fatty-acid cycle. Its role in insulin sensitivity and the metabolic disturbances of diabetes mellitus. Lancet 1:785-789

37. Pehmoller C, Brandt N, Birk JB et al (2012) Exercise alleviates lipid-induced insulin resistance in human skeletal musclesignaling interaction at the level of $\mathrm{TBC} 1$ domain family member 4. Diabetes 61:2743-2752
38. Vesali RF, Klaude M, Rooyackers O, Wernerman J (2005) Amino acid metabolism in leg muscle after an endotoxin injection in healthy volunteers. Am J Phys Endocrinol Metab 288:E360-E364

39. Vesali RF, Cibicek N, Jakobsson T, Klaude M, Wernerman J, Rooyackers O (2010) Protein metabolism in leg muscle following an endotoxin injection in healthy volunteers. Clin Sci (Lond) 118: 421-427

40. Fong Y, Matthews DE, He W, Marano MA, Moldawer LL, Lowry SF (1994) Whole body and splanchnic leucine, phenylalanine, and glucose kinetics during endotoxemia in humans. Am J Phys 266: R419-R425

41. Wernerman J, von der Decken A, Vinnars E (1986) Protein synthesis in skeletal muscle in relation to nitrogen balance after abdominal surgery: the effect of total parenteral nutrition. JPEN J Parenter Enteral Nutr 10:578-582

42. Caso G, Garlick PJ (2005) Control of muscle protein kinetics by acid-base balance. Curr Opin Clin Nutr Metab Care 8:73-76 